\title{
Long-Run Earnings Mobility among Low-Income Individuals
}

\author{
Brett Mullins ${ }^{1}$, Mark Rider ${ }^{2}$, David L. Sjoquist ${ }^{2} \&$ Sally Wallace ${ }^{2,3^{*}}$ \\ ${ }^{1}$ Department of Mathematics, Miami University, Oxford, Ohio \\ ${ }^{2}$ Department of Economics, Georgia State University, Atlanta, Georgia \\ ${ }^{3}$ The African Tax Institute, University of Pretoria, Pretoria, South Africa \\ * Sally Wallace, E-mail: swallace@gsu.edu
}

\begin{abstract}
We construct earnings mobility matrices for low-income individuals over 6-year and 13-year periods. Our sample of low-income individuals is drawn from the population of SNAP recipients in Georgia. Using Georgia administrative records, we identify SNAP participants in 2000 and their earnings for each year through 2013 using matched employment security records. We find that a substantial percentage of these individuals have zero earnings in both the initial and ending years. We find that there is a heavier concentration of males, whites, and disabled individuals with zero earnings in the initial and ending years than in the overall SNAP sample. This contradicts some of the characterizations of SNAP recipients in the popular press which often characterizes those stuck in poverty as single black mothers. In fact, the disabled represent the vast majority of those stuck in the no earnings category. Another interesting finding is that single mothers with zero earnings in 2000 have a greater probability, in some cases a much greater probability, of escaping the zero earnings category than the general population of SNAP recipients. We also find that individuals with positive earnings in the initial year experience substantial earnings mobility.
\end{abstract}

\section{Keywords}

redistribution, income mobility, poverty, expenditures, revenues

\section{Introduction}

There is a great deal of interest in recent trends in income inequality in the United States. A closely related issue is income mobility; that is the degree to which there are changes in the rank of households in the income distribution. Several recent papers measure income mobility in the general U.S. population; examples include Carroll, Joulfaian and Rider (2006), Auten and Gee (2009), Bradbury and Katz (2009), and Auten, Gee and Turner (2013). Studies of income mobility generally use individual income tax return data from the U.S. Internal Revenue Service, and thus consider households that file an income tax return. Therefore, individuals who do not file a federal individual income tax return, which is disproportionately compromised of low-income individuals, are not captured in such studies. To the best of our knowledge, no one has focused exclusively on the income mobility of low-income individuals or, to be more precise, on the income mobility of individuals with a low-income episode 
(Note 1). This is an unfortunate gap in the literature given the efforts to improve the long-run earnings mobility of low-income individuals through various programs including many publically funded income-support programs.

In this paper we examine the long-run earnings mobility of low-income individuals in Georgia. We identify low-income individuals by their participation in the Supplemental Nutrition Assistance Program (SNAP). As described in detail in the next section, we assemble administrative records for SNAP beneficiaries in Georgia and match them with Employment Security (ES202) records on wages, covering the period from January 2000 through December 2013 (Note 2). We believe we are the first to explore income transitions of program participants using population-based data. Many of the program participants in our sample may not file federal income tax returns because they have no taxable income to report and do not qualify for the Earned Income Tax Credit (EITC). Therefore, they would be missing from the existing studies based on federal personal income tax return data.

Briefly, we make a number of interesting and surprising findings. We find that a substantial percentage of SNAP recipients appear to be stuck or trapped with no earnings in the initial and terminal years of our observation period. We find that there is a heavier concentration of males, whites and disabled individuals with zero earnings in the initial and terminal years of the observation period than in the overall SNAP sample. This contradicts some of the characterizations of SNAP recipients in the popular media which often characterizes those stuck in poverty as single black mothers. In fact, the disabled represent the vast majority of those stuck in the no earnings category. Another interesting finding is that single mothers with zero earnings in 2000 have a greater probability, in some cases a much greater probability, of escaping the zero earnings category than the general population of SNAP recipients. We also find that individuals with positive earnings in the initial year experience substantial earnings mobility.

This study makes three contributions to the literature on earnings mobility. First, we examine the earnings mobility of low-earning individuals. Second, we use administrative data rather than survey data. The advantage of using administrative data is that they are less prone to reporting errors than survey data like the Panel Survey of Income Dynamics (PSID) or the Supplemental Income and Program Participation (SIPP). Third, we examine earnings mobility over a relatively long period of time. The long period allows us to explore how the degree of earnings mobility varies over time and allows us to account for a broader set of behaviors than previous studies of the effects of program participation, which generally focus on measuring the effects of social programs on women's short-run labor supply decisions.

A limitation of this research is that we have data for only one state. Although the data are not nationally representative, Georgia is a large state and in many ways is representative of an average or typical U.S. state. For example, in 2008 Georgia's median household income ranked $23^{\text {rd }}$ and the percent of the population with a BA degree or more and the percent that are homeowners are essentially the same as the national average. Given the nature of this study, we believe that the advantages of administrative 
data are worth the tradeoffs in terms of limited geographic coverage. An additional limitation of the data is that we cannot include low-income individuals who do not participate in SNAP.

The remainder of this paper is organized as follows. In the next section, we describe the data used in this study and discuss trends in program participation. In the third section, we construct earnings transition matrices for program beneficiaries to measure the effect of program participation on earnings mobility. A summary section concludes the paper.

\section{Data}

We utilize two datasets - administrative records for SNAP and for employment security. We use monthly records from the Georgia Department of Human Services (GDHS) for the period covering January 2000 through December 2013 (168 months), for participants in the SNAP program.

To study long-run earnings mobility among program participants, we need a measure of earnings over the entire observation period of this study. When an individual is no longer enrolled in SNAP, we can no longer rely on SNAP records to observe earnings. Therefore, we use administrative records on employment and wages from the Georgia Department of Labor (GDOL) to measure annual earnings for all years. These data come from Form ES202, which is filed by employers as required for the administration of the unemployment insurance program and consist of quarterly employment and wage reports for each employee of a firm. The form includes the wages paid by the firm to that employee during a given quarter and a unique identifier for each employee, which permits us to match these data to the SNAP records (Note 3). If an individual has multiple employers in a given period, we construct their total wage and salary income by quarter by identifying each firm for which the individual has reported earnings. This permits us to construct a measure of annual earnings for each individual in the sample by summing over the quarterly reports of wage and salary income for every employer of that individual during a given year.

We create our sample by selecting all individuals who are enrolled in SNAP during any month in 2000, and then determine annual earnings for years 2000, 2006 and 2013. Since we are interested in long-run earnings mobility of program participants, we want to consider individuals who would potentially be in the labor force during the entire period. We therefore exclude seniors and children from the sample. More specifically, we exclude individuals who would be at least sixty-five years old at any point during the sample period, i.e., individuals that are older than 51 in January 2000. The exclusion of seniors decreases the SNAP sample by 10.8 percent. For our purposes, an individual is designated a minor and excluded from the sample if the enrollee is less than eighteen years of age in January 2000. The exclusion of minors decreases the SNAP sample by 52.0 percent.

There are some disadvantages to using ES202 data to measure earnings mobility. First, we cannot observe out-of-state earnings nor can we observe non-wage income from any source (in-state or out-of-state). Furthermore, we cannot observe wages from the informal sector; that is, wages paid by an employer that for whatever reason does not file Form ES202 or fails to report or misreports the 
earnings of some or all of its employees. Finally, self-employed individuals are not required to file Form ES202; therefore, we cannot account for self-employment income.

In addition to examining the effect of program participation on long-run earnings mobility, we also examine the relationship between the duration of program participation and long-run earnings mobility. Therefore, we proceed below by briefly reviewing the evidence on the duration of program participation (Note 4). Figure 1 reports the number of individuals in our sample that have been continuously enrolled in SNAP for a given number of months. For example, the height of the top line (or the solid line) in Figure 1 reflects the number of individuals in a given month that have been enrolled for at least the previous 11 months, that is, for a least one year. Since we do not observe participation before January 2000, we cannot determine the length of enrollment for those who enrolled prior to January 2000; therefore, the top line starts on December 2000. For this reason, the length of enrollment should be viewed as a minimum period; some of the participants may have been enrolled for longer periods. Similarly, the other lines in Figure 1 represent longer minimum enrollment durations thus the lines begin on more recent dates. The five lines reflect continuous (uninterrupted) durations of at least 1 year (12 months) to at least 7 years ( 84 months). The general upward trend in all of these lines is in large part a function of general population growth in Georgia. However, there is no mistaking the steep increase in durations of one to four years that comes about during and after the Great Recession of 2007-2009. This pattern began to turn around in late 2012 and early 2013. The interaction between earlier (milder) recessions and SNAP were much less pronounced.

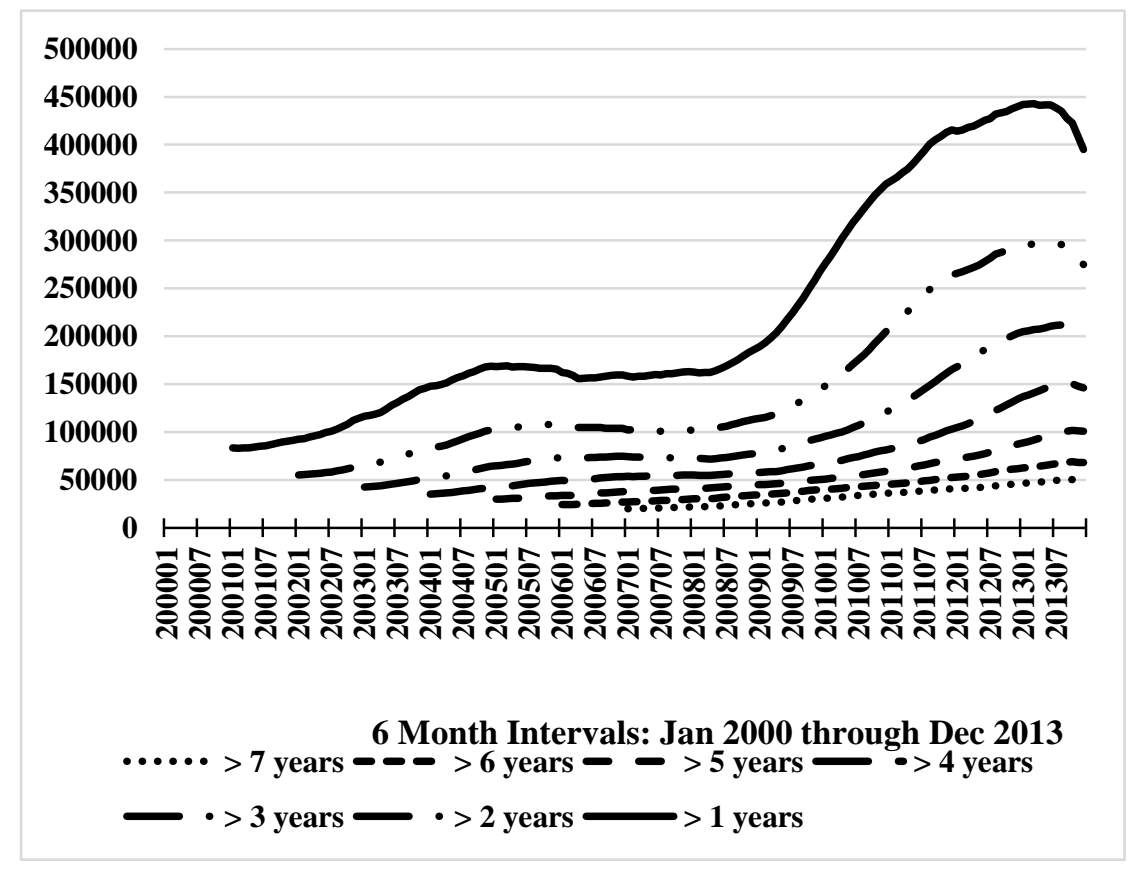

Figure 1. Consecutive Total SNAP Enrollment by Year

Source: Authors' calculations.

Note. Enrollment is the number of individuals. 
Overall, the duration for SNAP participants is long. In December 2008, 57.9 percent of enrollees were on SNAP for at least 12 months; whereas, in December 2013, 47.1 percent were enrolled for at least 12 months. There is also an increase in the number of participants for all SNAP durations over the sample period. For example, the proportion of total SNAP enrollees on the program for at least 3 years increases from 20.6 percent to 23.5 percent over this period.

\section{Earnings Mobility}

We now turn to our central question: what is the long-run earnings mobility among low-earnings individuals? Table 1 and Table 2 are earnings transition matrices. To construct an earnings transition matrix, we partition the sample into six earnings categories (a $\$ 0$ category and then quintiles) for year 2000 and for the ending year, either 2006 or 2013 (Note 5). To investigate the influence of time on earnings mobility, we observe the beginning and ending earnings of the sample for two time periods: 2000 to 2006 and 2000 to 2013.

More specifically, the rows in the tables correspond to the six earnings categories in year 2000, and the columns correspond to the six earnings categories in year 2006 or year 2013, where the earnings are inflation adjusted using the CPI-U in 2000 is equal to 1.00. Since a large proportion of the sample reports no earnings in either year (according to the ES202 data), we create a category in both years for those with no earnings. This category is labeled $\$ 0$ in the tables. We partition the remaining observations, that is, those individuals with nonzero earnings in both years, into quintiles. Each quintile has an equal number of individuals; these quintiles are labelled Q1 through Q5. The dollar amounts reported in the border rows and columns are the upper earnings bounds for the corresponding earnings category. For the reader's convenience, the five quintiles with nonzero earnings are identified with a thick border in each table. For ease of reference, we call this matrix the "nonzero-earnings" submatrix. Our interest is in the stationarity of earnings over time rather than the growth in earnings; thus, we are interested in the changes in the rank of individuals by their earnings. The earnings transition matrices are constructed so that when someone moves to a higher (lower) earnings quintile other than from the $\$ 0$ category, then someone else must move to a lower (higher) earnings quintile.

Table 1 and Table 2 are transition matrices for the two time periods, respectively, for the sample of 327,913 individuals. The top figure in each cell in Table 1 is the number of individuals in the respective quantile. For example, there are 88,895 individuals who report zero earnings in both years. The figure in brackets in each cell is the number of individuals as a percentage of the row sum. In other words, 79 percent of the 112,679 individuals in the $\$ 0$ category in year 2000 are still in the $\$ 0$ category in 2006 . Moving rightwards along the row labelled $\$ 0$ in Table 1, we see that approximately 7 percent of those without any earnings in 2000 experience sufficient earnings growth by 2006 to place them in the first (nonzero) quintile in 2006. This quintile corresponds to the column labeled Q1 in Table 1. Approximately, 3 percent of the individuals with no earnings in year 2000 experience sufficient earnings in 2006 to be in the fifth nonzero quintile (Q5) in 2006. By summing the percentages in the 
row labelled $\$ 0$ and the columns labelled Q1 through Q5, we see that approximately 21 percent of those with no earnings in 2000 experience sufficient earnings growth to escape the $\$ 0$ category by 2006 . This suggests that there is remarkably little earnings mobility among those individuals who are enrolled in SNAP in 2000 and begin in the $\$ 0$ earnings category in 2000.

Table 1. Earnings Mobility between January 2000 and December 2006

\begin{tabular}{llllllll}
\hline $\begin{array}{l}\text { Quintile } \\
\text { (threshold) }\end{array}$ & $\$ 0$ & Q1: & Q2: & Q3: & Q4: & Q5: & Row \\
\hline \$0 & $\mathbf{8 8 , 8 9 5}$ & 7,715 & 5,689 & 4,315 & 3,172 & 2,893 & 112,679 \\
& {$[\mathbf{7 9}]$} & {$[7]$} & {$[5]$} & {$[4]$} & {$[3]$} & {$[3]$} & {$[100]$} \\
Q1: & 22,945 & $\mathbf{7 , 2 9 1}$ & 5,095 & 3,498 & 2,414 & 1,803 & 43,046 \\
$\$ 1,480$ & {$[53]$} & {$[\mathbf{1 7}]$} & {$[12]$} & {$[8]$} & {$[6]$} & {$[4]$} & {$[100]$} \\
Q2: & 17,930 & 6,688 & $\mathbf{6 , 5 7 1}$ & 5,075 & 3,909 & 2,874 & 43,047 \\
$\$ 4,206$ & {$[42]$} & {$[16]$} & {$[\mathbf{1 5}]$} & {$[12]$} & {$[9]$} & {$[7]$} & {$[100]$} \\
Q3: & 14,371 & 5,187 & 6,704 & $\mathbf{6 , 8 1 1}$ & 5,712 & 4,262 & 43,047 \\
$\$ 7,915$ & {$[33]$} & {$[12]$} & {$[16]$} & {$[\mathbf{1 6}]$} & {$[13]$} & {$[10]$} & {$[100]$} \\
Q4: & 10,952 & 3,586 & 5,405 & 8,219 & $\mathbf{8 , 5 7 4}$ & 6,311 & 43,047 \\
$\$ 12,681$ & {$[25]$} & {$[8]$} & {$[13]$} & {$[19]$} & {$[\mathbf{2 0}]$} & {$[15]$} & {$[100]$} \\
Q5: & 12,681 & 2,215 & 3,219 & 4,764 & 8,902 & $\mathbf{1 4 , 5 3 9}$ & 43,047 \\
$\$ 28,984$ & {$[22]$} & {$[5]$} & {$[7]$} & {$[11]$} & {$[21]$} & {$[\mathbf{3 4}]$} & {$[100]$} \\
Column & 164,501 & 32,682 & 32,682 & 32,682 & 32,683 & 32,682 & 327,913 \\
Sums & {$[50]$} & {$[10]$} & {$[10]$} & {$[10]$} & {$[10]$} & {$[10]$} & {$[100]$} \\
\hline
\end{tabular}

Note. Authors' calculations.

1. The sample consists of the approximately 330 thousand individuals enrolled in SNAP in year 2000.

2. The top figure in each cell is the number of beneficiaries, and the figure in square brackets is the number in each cell as a percentage of the row sum.

3. The columns are the quintiles in 2000, and the rows are the quintiles in year 2006.

4. Q5 is the $99^{\text {th }}$ percentile rather than the $100^{\text {th }}$, since the income distributions are right skewed.

5. Due to rounding, the percentages reported in this table may not sum to 100.

Table 2. Earnings Mobility between January 2000 and December 2013

\begin{tabular}{llllllll}
\hline $\begin{array}{l}\text { Quintile } \\
\text { (threshold) }\end{array}$ & $\$ 0$ & Q1: & Q2: & Q3: & Q4: & Q5: & Row \\
\hline \multirow{2}{*}{$\$ 0$} & $\mathbf{9 5 , 8 8 1}$ & 4,634 & 3,911 & 3,236 & 2,667 & 2,350 & 112,679 \\
& {$[\mathbf{8 5}]$} & {$[4]$} & {$[3]$} & {$[3]$} & {$[2]$} & {$[2]$} & {$[100]$} \\
\multirow{2}{*}{ Q1: } & 29,382 & $\mathbf{4 , 4 4 5}$ & 3,314 & 2,427 & 1,898 & 1,580 & 43,046 \\
\hline
\end{tabular}




\begin{tabular}{llllllll}
\hline$\$ 1,480$ & {$[68]$} & {$[\mathbf{1 0}]$} & {$[8]$} & {$[6]$} & {$[4]$} & {$[4]$} & {$[100]$} \\
Q2: & 25,274 & 4,743 & $\mathbf{4 , 2 3 6}$ & 3,412 & 2,891 & 2,491 & 43,047 \\
$\$ 4,206$ & {$[59]$} & {$[11]$} & {$[\mathbf{1 0}]$} & {$[8]$} & {$[7]$} & {$[6]$} & {$[100]$} \\
Q3: & 22,054 & 4,172 & 4,747 & $\mathbf{4 , 6 5 3}$ & 4,032 & 3,391 & 43,047 \\
$\$ 7,915$ & {$[51]$} & {$[10]$} & {$[11]$} & {$[\mathbf{1 1}]$} & {$[9]$} & {$[8]$} & {$[100]$} \\
& 18,596 & 3,503 & 4,600 & 5,911 & $\mathbf{5 , 7 5 2}$ & 4,685 & 43,047 \\
Q4: \$12,681 & {$[43]$} & {$[8]$} & {$[11]$} & {$[14]$} & {$[\mathbf{1 3}]$} & {$[11]$} & {$[100]$} \\
& 16,555 & 2,536 & 3,228 & 4,396 & 6,795 & $\mathbf{9 , 5 3 7}$ & 43,047 \\
Q5: \$28,984 & {$[38]$} & {$[6]$} & {$[8]$} & {$[10]$} & {$[16]$} & {$[\mathbf{2 2}]$} & {$[100]$} \\
Column & 207,740 & 24,033 & 24,036 & 24,035 & 24,035 & 24,034 & 327,913 \\
Sums & {$[63]$} & {$[7.3]$} & {$[7.3]$} & {$[7.3]$} & {$[7.3]$} & {$[7.3]$} & {$[100]$} \\
\hline
\end{tabular}

Note. 1. The sample consists of the approximately 3.5 million individuals enrolled in SNAP in year 2000.

2. The top figure in each cell is the number of beneficiaries, and the figure in square brackets is the number in each cell as a percentage of the row sum.

3. The columns are the quintiles in 2000, and the rows are the quintiles in year 2013.

4. Q5 is the $99^{\text {th }}$ percentile rather than the $100^{\text {th }}$, since the income distributions are right skewed.

5. Due to rounding, the percentages reported in this table may not sum to 100 .

Since there is so much information in a transition matrix, it would be tedious to try to describe all of it. To facilitate comparisons among alternative subsamples, we construct an index of earnings mobility, denoted $M$, as specified in equation (1) (Note 6).

$$
M=k^{-1}\left[\sum_{i=1}^{k} 100-P_{i i}\right]
$$

where $P_{i i}$ is the row percentage of individuals in the ith row and column $(\mathrm{i}=1, \ldots, \mathrm{k})$ of the mobility matrix. The resulting index is bounded between zero and 100 , and mobility is positively related to the value of the index. This index of earnings mobility rests on the fact that those experiencing no earnings mobility are in the cells lying on the diagonal of Table 1. For example, an index equal to 20 means that 20 percent of the sample are in a different quantile in 2006 than the one in which they started in 2000. While the interpretation of this index is straightforward and intuitive, it does discard information about earnings mobility in the off diagonal cells (Note 7).

The mobility index ("M") for Table 1 is approximately equal to 70 . This is indicative of a relatively high degree of earnings mobility among all of the individuals in the sample. The mobility index for the nonzero-earnings submatrix of Table 1 , henceforth denoted $M_{-\$ 0}$, is equal to 80 (Note 8 ). In other words, mobility among the individuals in the nonzero-earnings subsample is greater than for the sample as a whole ( 80 versus 70 , respectively). The mobility index for the submatrix or cell reporting no earnings in either year, henceforth denoted $M_{\$ 0}$ and referred to as the "zero-earnings submatrix", is equal to 21 , meaning that 21 percent of the sample that begins in the $\$ 0$ quantile in 2000 is no longer in Published by SCHOLINK INC. 
the $\$ 0$ quantile in 2006 while 79 percent remains in the $\$ 0$ quantile (Note 9). This is indicative of relatively little earnings mobility among this group or a high degree of stationarity.

Table 2 is constructed with the same initial sample of 327,913 individuals. However, Table 2 compares the earnings categories of these individuals in year 2000 with their earnings categories in 2013. The mobility index $(M)$ for Table 2 is equal to 75 , which is slightly greater than the corresponding value for Table 1 . The mobility index $\left(M_{-\$ 0}\right)$ for the nonzero-earnings submatrix of Table 2 is 87 . This value is also greater than the corresponding value for Table 1 . Finally, the mobility index $\left(M_{\$ 0}\right)$ for the zero-earnings submatrix is equal to 15 . This is somewhat smaller than the corresponding value for Table 1. These patterns should come as little surprise. They show, just as one would expect, that the rate of earnings mobility is greater over a 13-year time period than over a 6-year period, except for the $\$ 0$ earnings group. As we shall see, this pattern is repeated throughout the following analysis of earnings mobility for the various subsamples considered below.

\subsection{Additional Analysis}

We conducted several analyses.

\subsubsection{Subsamples}

To gain insight into SNAP enrollment duration on earnings mobility, we further partition our sample into three subsamples: those who drop out of SNAP prior to December 2006, the halfway point in the sample period; those who drop out after December 2006 but before December 2013; and those who are continuously enrolled in SNAP for the entire sample period. Table 3 reports the mobility indexes from the earnings transition matrices for these three subsamples. In addition, we report the number of observations in each subsample as well as the number of observations in the $\$ 0-\$ 0$ cell. For ease of reference, we also report the corresponding information from Table 1 and Table 2.

Table 3. Summary of Income Mobility Measures for Subsamples

\begin{tabular}{lllllll}
\hline Sample & $\begin{array}{l}\text { Ending } \\
\text { Year }\end{array}$ & $\begin{array}{l}\text { Sample } \\
\text { Size }\end{array}$ & $\begin{array}{l}\text { Percent in } \\
\$ 0-\$ 0 \text { cell }^{1}\end{array}$ & M & $\mathrm{M}_{\$ 0}$ & $\mathrm{M}_{-\$ 0}$ \\
\hline Table 1 & 2006 & 327,913 & 27.1 & 70 & 21 & 80 \\
Table 2 & 2013 & 327,913 & 29.2 & 75 & 15 & 87 \\
& 2006 & 300,703 & 25.1 & 70 & 22 & 80 \\
$\begin{array}{l}\text { Dropped-out prior to December } \\
\text { 2006 }\end{array}$ & 2013 & 300,703 & 27.3 & 75 & 16 & 87 \\
& 2006 & 16,230 & 45.0 & 68 & 15 & 78 \\
$\begin{array}{l}\text { Dropped-out between December } \\
\text { 2006 and December 2013 }\end{array}$ & 2013 & 16,230 & 46.6 & 73 & 15 & 86 \\
\hline
\end{tabular}




\begin{tabular}{lcccccc}
\hline & 2006 & 10,980 & 54.9 & 69 & 10 & 81 \\
Enrolled for entire sample period & 2013 & 10,980 & 57.1 & 74 & 7 & 88 \\
\hline
\end{tabular}

${ }^{1}$ The figures in this column are percentages of the sample size reported in the adjacent column. The figures reported in brackets in the cells labelled $\$ 0$-\$0 in Table 2 and Table 3 are percentages of the row sum.

The vast majority, approximately 91.7 percent, of individuals enrolled in SNAP in 2000 drop out of the program prior to December 2006, and only 3.3 percent of the sample are enrolled in SNAP for the entire 6-year period. There is a visible trend for those individuals with longer exposures to SNAP. As the exposure to SNAP increases, the proportion of the enrollees in the $\$ 0$ - $\$ 0$ category increases. For example, the $\$ 0-\$ 0$ category makes up around 29.2 percent of the SNAP sample reported in Table 2. In contrast, the $\$ 0-\$ 0$ earnings category makes up approximately 57.1 percent of the sample enrolled in SNAP for the entire 13-year sample period (last row in Table 3). This pattern is reinforced by the mobility indexes reported in the column labelled $M_{\$ 0}$ in Table 3 which shows an inverse relationship between the probability of escaping the $\$ 0$ category in 2013 and the length of SNAP exposure. Note that we are not suggesting that longer exposures to SNAP reduces the probability of escaping the $\$ 0$ category; in fact, one would expect the causation to run in the opposite direction. On the other hand, there is little difference in the values of $\mathrm{M}_{-\$ 0}$ as the length of exposure to SNAP increases.

There appears to be two different groups or experiences among SNAP beneficiaries. A large proportion of SNAP beneficiaries in the $\$ 0$ category in year 2000, upwards of 80 to 90 percent, appear to be trapped in the $\$ 0$ category. In contrast, it is evident from examining the mobility indexes reported in the column labelled $M_{-\$ 0}$ in Table 3 that those with nonzero earnings in 2000 enjoy considerable earnings mobility. This index varies between 78 and 81 over the six-year time period and 86 and 88 over the 13-year time period. Although the value of the nonzero-earnings mobility index $\left(M_{-\$ 0}\right)$ increases from 80 to 87 as the time period increases from 6 to 13 years, the value of the mobility index appears to be independent of the length of time the beneficiary is enrolled in the SNAP program.

\subsubsection{TANF Recipients}

We also drew a sample of low income individuals using TANF administrative records and constructed earnings transition matrices. The results using the TANF sample are generally consistent with those reported for the SNAP sample, and thus we do not report the TANF transition matrices. There are two differences. First, the earnings mobility indexes are slightly larger for the TANF sample, and, second, a smaller share of the TANF sample is in the $\$ 0-\$ 0$ category. These two differences may reflect the time limits on TANF benefits (Note 10).

\subsubsection{Mobility Patterns for Other Cohorts}

Thus far we only track one cohort, namely adults enrolled in SNAP in the year 2000. Further analysis is 
required to determine whether the experience of this cohort is representative for that of other cohorts during the observation period of this study. Since there is only one 13-year cohort in our sample, we focus on the 6-year cohorts. We construct earnings transition matrices for the remaining 6-year cohorts, corresponding to 2001-2007, 2002-2008, ..., 2007-2013. We use a test statistic devised by Trede (1999) to determine if the rates of earnings mobility observed for the 2000-2006 cohort is representative of the rates observed in the seven subsequent 6 -year cohorts. We can only conduct this statistical test for the set of all program participants in a given year and the set of individuals enrolled consecutively for less than six years. As before, we exclude children and retirees from the samples. We construct transition matrices by selecting individuals who participated in SNAP for at least one month in the initial year of the 6-year period used to construct a given transition matrix.

Trede (1999) describes a statistical method for testing differences in summary measures of transition matrices. Given the large number of observations in our samples, we revise the test statistic to reduce its sensitivity to the sample size. For cohorts 2000 to 2006 and $t$ to $t+6$, where $t=2001, \ldots, 2007$, the test statistic (denoted by $\mathrm{S}$ ) is given by the following expression:

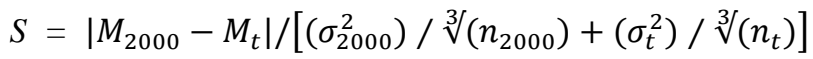

$M_{t}$ is the value of the mobility index for the cohort beginning in year $t$ (=2001 through 2007) as previously defined, $\sigma_{t}^{2}$ is the variance of $M_{t}$ and $n_{t}$ is the number of observations in the cohort beginning in year $t$. With $M$ and $n$ given, we use the delta method to estimate the variance of $M$. This measure deviates from Trede's insofar as his statistic uses the number of observations rather than its cube root; however, both statistics are asymptotically equivalent. We use the cube root of the number of observations to reduce the sensitivity of Trede's test statistic to the sample size.

Table 4 presents estimates of equation (Note 11). We test the null hypothesis $H_{0}: M_{2000}=M_{t}$ and the alternative hypothesis $H_{A}: M_{2000} \neq M_{t}$, where the subscript $t$ refers to a 6-year cohort beginning in 2001 through 2007. Notice that the test statistic for five of the seven cohorts are below the 95-percent critical value, meaning that the differences in the indexes are statistically indistinguishable from zero at the 5 percent significance level. Note, in particular, that this implies that earnings mobility among the low-earnings individuals in our sample did not change during the Great Recession.

Table 4. Testing Mobility Measure for Total Enrollment of Additional Cohorts

\begin{tabular}{llll}
\hline Cohort & Sample Size $(\mathrm{n})$ & Variance $\left(\hat{\sigma}^{2}\right)$ & Test Statistic $^{1}$ \\
\hline $2000-06$ & 132,681 & 0.180 & \\
$2001-07$ & 148,992 & 0.187 & 0.248 \\
$2002-08$ & 174,244 & 0.187 & 1.423 \\
$2003-09$ & 205,786 & 0.178 & 2.939 \\
$2004-10$ & 226,127 & 0.176 & 1.867 \\
\hline
\end{tabular}




\begin{tabular}{llll}
\hline $2005-11$ & 252,140 & 0.176 & 1.884 \\
$2006-12$ & 243,463 & 0.175 & 2.093 \\
$2007-13$ & 248,312 & 0.182 & 1.231 \\
\hline
\end{tabular}

${ }^{1}$ The critical value is 1.96 at the 5-percent significance level Characteristics of the sample.

An important consideration related to earnings mobility is whether mobility is different among types of individuals differentiated by household size, gender, and race. Some popular press and political debates have painted welfare recipients with a broad brush that implies individuals receiving SNAP (or TANF) benefits are more heavily represented by single mothers and non-Caucasians. In designing public policies such as SNAP, it is important to know the demographics of the recipient population. In the context of this paper, that means the demographics of those with and without earnings mobility. What do those "stuck" in the $\$ 0$ - $\$ 0$ category look like and how do they move through the earnings distribution over time? Table 5 presents the characteristics of the full sample and those individuals in the $\$ 0-\$ 0$ earning category in Table 1 and Table 2. Table 6 shows the characteristics of those individuals with dependent children, i.e., a child 17 years of age or younger in 2000. Any head-of-household in a family in which there is a dependent child is assumed to be the "parent" of that dependent child. Comparing the concentration of characteristics in the overall sample (the first two data columns of Table 5 and Table 6) to the $\$ 0$ - $\$ 0$ cell, we find that there is a heavier concentration of males, whites, and disabled individuals in the $\$ 0-\$ 0$ cells than in the overall SNAP sample. This alone contradicts some of the characterizations of SNAP recipients in the popular press which often characterizes those stuck in poverty as single black mothers. The disabled represent the vast majority of the observations in the $\$ 0-\$ 0$ category in Table 5 and Table 6 .

Table 5. Characteristics of Individuals

\begin{tabular}{|c|c|c|c|c|c|c|c|c|}
\hline \multirow[b]{3}{*}{ Category } & \multicolumn{2}{|l|}{ Sample } & \multicolumn{3}{|c|}{$\$ 0-\$ 0$ in $2000-2006$} & \multicolumn{3}{|c|}{$\$ 0-\$ 0$ in $2000-2013$} \\
\hline & & Percent & & Percent & Percent of & & Percent & Percent of \\
\hline & Total & of Total & Total & of Total & Category & Total & of Total & Category \\
\hline Males & 86,689 & 26.4 & 31,393 & 35.3 & 36.2 & 33,161 & 34.6 & 38.3 \\
\hline Females & 241,224 & 73.6 & 57,502 & 64.7 & 23.8 & 62,720 & 65.4 & 26.0 \\
\hline White & 115,556 & 35.2 & 38,541 & 43.4 & 33.4 & 41,329 & 43.1 & 35.8 \\
\hline Black & 209,853 & 64.0 & 49,448 & 55.6 & 23.6 & 53,615 & 55.9 & 25.5 \\
\hline Other Race/Ethnicity & 2,504 & 0.8 & 905 & 1.0 & 36.1 & 937 & 1.0 & 37.4 \\
\hline Married & 50,508 & 15.4 & 15,192 & 17.1 & 30.1 & 16,234 & 16.9 & 32.1 \\
\hline Disabled & 37,757 & 11.5 & 29,604 & 33.3 & 78.4 & 30,580 & 31.9 & 81.0 \\
\hline Married Female & 27,663 & 8.4 & 8,560 & 9.6 & 30.9 & 9,257 & 9.7 & 33.5 \\
\hline Black Single Female & 153,762 & 46.9 & 30,792 & 34.6 & 20.0 & 33,813 & 35.3 & 22.0 \\
\hline
\end{tabular}

Published by SCHOLINK INC 


\begin{tabular}{lllllllll}
\hline White Single Female & 58,497 & 17.8 & 17,696 & 19.9 & 30.3 & 19,179 & 20.0 & 32.8 \\
Other Race Single Female & 1,302 & 0.4 & 454 & 0.5 & 34.9 & 471 & 0.5 & 36.2 \\
Married Male & 22,845 & 7.0 & 6,632 & 7.5 & 29.0 & 6,977 & 7.3 & 30.5 \\
Black Single Male & 40,501 & 12.4 & 14,638 & 16.5 & 36.1 & 15,535 & 16.2 & 38.4 \\
White Single Male & 22,940 & 7.0 & 9,976 & 11.2 & 43.5 & 10,496 & 10.9 & 45.8 \\
Other Race Single Male & 403 & 0.1 & 147 & 0.2 & 36.5 & 153 & 0.2 & 38.0 \\
Disabled Female & 24,516 & 7.5 & 19,404 & 21.8 & 79.1 & 20,055 & 20.9 & 81.8 \\
Disabled Black & 23,676 & 7.2 & 17,960 & 20.2 & 75.9 & 18,602 & 19.4 & 78.6 \\
Disabled White & 13,864 & 4.2 & 11,465 & 12.9 & 82.7 & 11,794 & 12.3 & 85.1 \\
Disabled Other Race & 217 & 0.1 & 179 & 0.2 & 82.5 & 184 & 0.2 & 84.8 \\
Disabled Male & 13,241 & 4.0 & 10,200 & 11.5 & 77.0 & 10,525 & 11.0 & 79.5 \\
Disabled Married & 3,538 & 1.1 & 2,832 & 3.2 & 80.0 & 2,927 & 3.1 & 82.7 \\
Disabled Single & 34,219 & 10.4 & 26,772 & 30.1 & 78.2 & 27,653 & 28.8 & 80.8 \\
With Dependent Child & 249,007 & $\mathbf{7 5 . 9}$ & $\mathbf{5 2 , 1 7 8}$ & 58.7 & 21.0 & 57,280 & 59.7 & 23.0 \\
TOTAL & $\mathbf{3 2 7 , 9 1 3}$ & $\mathbf{1 0 0 . 0}$ & $\mathbf{8 8 , 8 9 5}$ & $\mathbf{1 0 0 . 0}$ & $\mathbf{2 7 . 1}$ & $\mathbf{9 5 , 8 8 1}$ & $\mathbf{1 0 0 . 0}$ & $\mathbf{2 9 . 2}$ \\
\hline
\end{tabular}

Table 6. Characteristics of Individuals with a Dependent Child

\begin{tabular}{|c|c|c|c|c|c|c|c|c|}
\hline & \multicolumn{2}{|l|}{ Sample } & \multicolumn{3}{|c|}{$\$ 0-\$ 0$ in $2000-2006$} & \multicolumn{3}{|c|}{$\$ 0-\$ 0$ in $2000-2013$} \\
\hline & & Percent & & Percent & Percent of & & Percent & Percent of \\
\hline & Total & of Total & Total & of Total & Category & Total & of Total & Category \\
\hline Males & 45,653 & 18.3 & 12,439 & 23.8 & 27.2 & 13,195 & 23.0 & 28.9 \\
\hline Females & 203,354 & 81.7 & 39,739 & 76.2 & 19.5 & 44,085 & 77.0 & 21.7 \\
\hline White & 88,838 & 35.7 & 23,690 & 45.4 & 26.7 & 25,828 & 45.1 & 29.1 \\
\hline Black & 158,080 & 63.5 & 27,792 & 53.3 & 17.6 & 30,728 & 53.6 & 19.4 \\
\hline Other Race/Ethnicity & 2,089 & 0.8 & 696 & 1.3 & 33.3 & 724 & 1.3 & 34.7 \\
\hline Married & 44,995 & 18.1 & 12,362 & 23.7 & 27.5 & 13,263 & 23.2 & 29.5 \\
\hline Disabled & 17,107 & 6.9 & 12,843 & 24.6 & 75.1 & 13,403 & 23.4 & 78.3 \\
\hline Married Female & 24,624 & 9.9 & 6,972 & 13.4 & 28.3 & 7,569 & 13.2 & 30.7 \\
\hline Black Single Female & 130,520 & 52.4 & 21,049 & 40.3 & 16.1 & 23,539 & 41.1 & 18.0 \\
\hline White Single Female & 47,082 & 18.9 & 11,358 & 21.8 & 24.1 & 12,598 & 22.0 & 26.8 \\
\hline Other Race Single & 1,128 & 0.5 & 360 & 0.7 & 31.9 & 379 & 0.7 & 33.6 \\
\hline \multicolumn{9}{|l|}{ Female } \\
\hline Married Male & 20,371 & 8.2 & 5,390 & 10.3 & 26.5 & 5,694 & 9.9 & 28.0 \\
\hline Black Single Male & 13,683 & 5.5 & 3,504 & 6.7 & 25.6 & 3,746 & 6.5 & 27.4 \\
\hline White Single Male & 11,375 & 4.6 & 3,485 & 6.7 & 30.6 & 3,693 & 6.4 & 32.5 \\
\hline Other Race Single Male & 224 & 0.1 & 60 & 0.1 & 26.8 & 62 & 0.1 & 27.7 \\
\hline
\end{tabular}

Published by SCHOLINK INC. 


\begin{tabular}{lllllllll}
\hline Disabled Female & 13,679 & 5.5 & 10,356 & 19.8 & 75.7 & 10,814 & 18.9 & 79.1 \\
Disabled Black & 11,441 & 4.6 & 8,276 & 15.9 & 72.3 & 8,669 & 15.1 & 75.8 \\
Disabled White & 5,556 & 2.2 & 4,478 & 8.6 & 80.6 & 4,643 & 8.1 & 83.6 \\
Disabled Other Race & 110 & 0.0 & 89 & 0.2 & 80.9 & 91 & 0.2 & 82.7 \\
Disabled Male & 3,428 & 1.4 & 2,487 & 4.8 & 72.5 & 2,589 & 4.5 & 75.5 \\
Disabled Married & 2,374 & 1.0 & 1,833 & 3.5 & 77.2 & 1,908 & 3.3 & 80.4 \\
Disabled Single & 14,733 & 5.9 & 11,010 & 21.1 & 74.7 & 11,495 & 20.1 & 78.0 \\
TOTAL & $\mathbf{2 4 9 , 0 0 7}$ & $\mathbf{1 0 0 . 0}$ & $\mathbf{5 2 , 1 7 8}$ & $\mathbf{1 0 0 . 0}$ & $\mathbf{2 1 . 0}$ & $\mathbf{5 7 , 2 8 0}$ & $\mathbf{1 0 0 . 0}$ & $\mathbf{2 3 . 0}$ \\
\hline
\end{tabular}

\subsubsection{Earnings Mobility among Single Mothers}

Given the interest in the effect of program participation on the labor supply of single mothers, we use these data to examine the long-run earnings mobility of single mothers. Using the SNAP and TANF administrative records, we identified unmarried females who are also a mother or guardian of a child. Summary information for this subsample is reported in Table 7. The proportion of the full sample who are single mothers is 39 . Interestingly, single mothers are slightly underrepresented in the $\$ 0-\$ 0$ categories relative to their shares in the SNAP and TANF samples. Comparing the values of $M$ and $M_{-\$ 0}$ for single mothers with the corresponding indexes reported in Table 3, there are only slight differences, and there is no discernible pattern in these differences. Comparing the values of $M_{\$ 0}$ for single mothers with the corresponding indexes reported in Table 3, it appears that single mothers with zero earnings in 2000 have a greater probability, in some cases a much greater probability, of escaping the zero category than the general population of program participants.

Table 8 reports tests of the hypotheses that single mothers do not experience differential earnings mobility with regard to both enrollment status and length of enrollment. We calculate transition matrices for individuals who are not single mothers and calculate the test statistic $S$ to compare the mobility measures of these two subsamples. Interestingly and unexpectedly, we fail to reject the null hypothesis of no differential earnings mobility at the 5-percent significance level for all statuses and lengths of enrollment. This suggests that the earnings mobility of single mothers is not statistically distinguishable at the 5-percent significance level from those who are not single mothers. This result is somewhat surprising given that the literature generally finds that single mothers experience worse economic outcomes than two-parent households [Povich, Roberts and Mather (Winter 2013-2014)].

Table 7. Summary Measures of Income Mobility among Single Mothers

\begin{tabular}{lllllll}
\hline \multirow{2}{*}{ Sample } & $\begin{array}{l}\text { Ending } \\
\text { Year }\end{array}$ & $\begin{array}{l}\text { Sample } \\
\text { Size }\end{array}$ & $\begin{array}{l}\text { Percent in } \\
\$ 0-\$ 0 \text { cell }^{1}\end{array}$ & M & $\mathbf{M}_{\$ 0}$ & $\mathbf{M}_{-\$ 0}$ \\
\hline \multirow{2}{*}{ Full sample } & 2006 & 127,654 & 17.7 & 70 & 29 & 78 \\
& 2013 & 127,654 & 19.7 & 74 & 21 & 85 \\
\hline
\end{tabular}




\begin{tabular}{lllllll}
\hline \multirow{2}{*}{ Dropped-out prior to December 2006 } & 2006 & 114,345 & 16.0 & 70 & 30 & 78 \\
& 2013 & 114,345 & 18.0 & 75 & 22 & 85 \\
Dropped-out between December 2006 and & 2006 & 8,030 & 28.2 & 69 & 24 & 78 \\
December 2013 & 2013 & 8,030 & 29.9 & 74 & 19 & 85 \\
& 2006 & 5,279 & 38.0 & 70 & 19 & 80 \\
Enrolled for entire sample period & 2013 & 5,279 & 40.9 & 75 & 12 & 87 \\
\hline
\end{tabular}

${ }^{1}$ The figures in this column are percentages of the sample size reported in the adjacent column.

Table 8. Testing Earnings Mobility for Single Mothers against That of All Other Individuals ${ }^{1}$

\begin{tabular}{lllll}
\hline Sample & Ending Year & $\begin{array}{l}\text { Mobility } \\
\text { Measure }(\mathrm{M})^{2}\end{array}$ & ${\text { Variance }\left(\hat{\sigma}^{2}\right)}^{\text {Test Statistic }}$ \\
\hline Full sample & 2006 & 71 & 0.182 & 1.215 \\
& 2013 & 76 & 0.128 & 1.839 \\
Dropped-out prior to & 2006 & 71 & 0.177 & 1.090 \\
December 2006 & 2013 & 76 & 0.125 & 1.671 \\
Dropped-out between December 2006 & 2006 & 69 & 0.351 & 0.018 \\
and December 2013 & 2013 & 74 & 0.257 & 0.099 \\
& 2006 & 70 & 0.397 & 0.124 \\
Enrolled for entire sample period & 2013 & 75 & 0.270 & 0.101 \\
\hline
\end{tabular}

${ }^{1}$ This table presents the results of testing the null hypothesis that the earnings mobility measure for a given cohort of single mothers is equal to the earnings mobility measure for all other individuals who are not single mothers for a given cohort.

${ }^{2}$ This column refers to the earnings mobility measure for all other individuals who are not single mothers.

${ }^{3}$ The critical value is 1.96 at the 5-percent significance level.

\subsubsection{Recent SNAP Enrollees}

The sample used for Tables 1 and 2 consists of all SNAP recipients who were in the program in 2000, including those who may have been in the program for many years prior to 2000 . We created an alternative sample that consists of individuals in the SNAP file in 2001 who were not in the file in 2000. This file can be thought of as "new" low income individuals. We created earnings transition matrices for this new sample for each of the two periods 2001-2007 and 2007-2013. The matrices are very similar to those for the original sample. Because they are so similar we do not report them. 


\section{Summary and conclusions}

We use administrative data to examine the earnings mobility of SNAP beneficiaries in the state of Georgia during the period January 2000 through December 2013. Based on the evidence reported here, it appears that there are two different groups or experiences in our sample. There appears to be little earnings mobility among individuals with zero earnings in the initial year (2000). For those individuals with nonzero earnings in the initial year, there appears to be substantial earnings mobility. Unfortunately, a substantial proportion of our sample appears to be trapped in the zero-earnings category over significant periods of time. We find that there is a heavier concentration first of all of disabled individuals than in the overall SNAP population. Other high $\$ 0$-\$0 categories include males and whites, married or not. These findings contradict some of the characterizations of SNAP recipients in the popular press which often characterizes those stuck in poverty as single black mothers. The disabled represent the vast majority of the observations in stuck in poverty or in the $\$ 0$ - $\$ 0$ category. Another interesting finding is that single mothers with zero earnings in 2000 have a greater probability, in some cases a much greater probability, of escaping the zero earnings category than the general population of program participants.

It is difficult to identify specific causes for these findings. Without additional demographic, education, and other information, we cannot speculate specific causes for movement among a certain set of recipients and the trap that others contend with. Future research will seek to identify causal relationships between earnings mobility and social programs. This paper is useful in identifying sub-populations that deserve further study and potentially dispels some preconceived notions of individuals who receive public benefits. In addition, the results in this paper ought to be approached with some caution. We are not able to account for individuals who leave the state, are institutionalized for one reason or another, or work in the informal sector. Furthermore, we do not have a counterfactual group with which to benchmark the experiences of our sample of program beneficiaries. The individuals in our sample may be faring better or worse in terms of long-run earnings mobility than a sample of otherwise identical individuals with no exposure to these programs.

\section{Acknowledgments}

We express our gratitude to Lakshmi Pandey for his assistance with creating the data files, and we gratefully acknowledge the financial support of the Dan Sweat Chair.

\section{References}

Auten, G., \& Geoffrey, G. (2009). Income Mobility in the United States: New Evidence from Income Tax Data. National Tax Journal, 62(2), 301-328.

Auten, G., Geoffrey, G., \& Nicholas, T. (2013). Income Inequality, Mobility, and Turnover at the Top in the US, 1987-2010. The American Economic Review, 103(3), 168-172.

Blank, R. M., David, C., \& Phillip, R. (1999). Financial Incentives for Increasing Work and Income 
among Low-Income Families. National Bureau of Economic Research working paper.

Bradbury, K., \& Jane, K. (2009). Trends in U.S. Family Income Mobility, 1967-2004. FRB of Boston Working Paper.

Carroll, R., David, J., \& Mark, R. (2006). Income Mobility: The Recent American Experience. Andrew Young School of Policy Studies Research Paper Series. Retrieved from http://www.ssrn.com/abstract=976055 or http://dx.doi.org/10.2139/ssrn.976055

Eissa, N., \& Jeffrey, B. L. (1996). Labor Supply Response to the Earned Income Tax Credit. The Quarterly Journal of Economics, 112(2), 605-637.

Ellwood, D. T. (2000). The Impact of the Earned Income Tax Credit and Social Policy Reforms on Work, Marriage, and Living Arrangements. National Tax Journal, 53(4), 1063-1106.

Formby, J. P., James, S. W., \& Buhong, Z. (2004). Mobility Measurement, Transition Matrices, and Statistical Inference. Journal of Econometrics, 120, 181-205.

Grogger, J. (2003). The Effects of Time Limits, the EITC, and Other Policy Changes on Welfare Use, Work, and Income Among Female-Headed Families. The Review of Economics and Statistics, 85(2), 394-408.

Loprest, P. (2012). How Has the TANF Caseload Changed Over Time? Washington, DC: Office of Planning, Research and Evaluation, Urban Institute.

Meyer, B. D. (2002). Labor Supply at the Extensive and Intensive Margins: The EITC, Welfare, and Hours Worked. The American Economic Review, 92(2). 373-379. Papers and Proceedings of the One Hundred Fourteenth Annual meeting of the American Economic Association. Retrieved from http://www.jstor.org/sTable/3083435

Meyer, B. D., \& Dan, T. R. (2001). Welfare, the Earned Income Tax Credit, and the Labor Supply of Single Mothers. The Quarterly Journal of Economics, 116(3), 1063-1114. Retrieved from http://www.jstor.org/sTable/2696426

Mullins, B., Mark, R., David, L. S., \& Sally, W. (2015). Trends in TANF and SNAP Participation in Georgia. Fiscal Research Center, Andrew Young School of Policy Studies, Georgia State University.

Povich, D., Brandon, R., \& Mark, M. (2013-2014 Winter). Low-Income Working Mothers and State Policy: Investing for a Better Economic Future. Policy Brief. The Working Poor Families Project. Retrieved from http://www.workingpoorfamilies.org/wp-content/uploads/2014/02/WPFP_LowIncome-Working-Mothers-Report_021214.pdf

Saez, E. (2010). Do Taxpayers Bunch at Kink Points? American Economic Journal: Economic Policy, 2(3), 180-212.

Trede, M. (1999). Statistical Inference for Measures of Income Mobility. Journal of Economics and Statistics, 218, 473-90. 


\section{Notes}

Note 1. There is an extensive literature on intergenerational income mobility and lifetime income mobility. The methodology employed in this study differs from those approaches in that we focus on the income mobility of individuals (families) over a given period of time.

Note 2. The ES202 is now more commonly referred to as the Quarterly Census of Employment and Wages (QCEW).

Note 3. We create a categorical variable for each month that indicates an individual's enrollment status with regard to SNAP; this variable is extracted from the Department of Human Services datasets. An individual is identified by a unique identifier; however, not all the identifiers could be matched in both datasets. Therefore, a number of individuals are excluded from the dataset. The proportion of unmatched identifiers in the SNAP dataset varies between 0.5 and 4.5 percent for a given month.

Note 4. The SNAP dataset can be used to explore trends in the usage of these two programs. We do not describe the enrollment trends for Georgia here because they are similar to those reported for the U.S. as a whole, which have been described in Loprest (2012) and Mullins et al (2015).

Note 5. Formby et al. (2004) describe alternative ways of constructing mobility matrices.

Note 6. Formby et al. (2004) describe alternative measures of income mobility as well as their relative strengths and weaknesses.

Note 7. To make matters more concrete, consider the following hypothetical example. Suppose there is no earnings mobility. In this case, the percentage in each of the cells lying along the main diagonal of the matrix will be equal to 100 , indicating that 100 percent of the individuals in a given earnings quantile in year 2000 are in the same earnings quantile in year 2006. The sum of these figures would equal 600 , subtracting this sum from 600 , and dividing the result by six results in a mobility index equal to zero, meaning that there is no earnings mobility. Taking the opposite extreme, suppose no one is in the same earnings quantile in year 2006 as in year 2000. In this case, the percentage in each of the cells along the main diagonal would be equal to zero, and the mobility index would be equal to 100 , indicating "complete" earnings mobility.

Note 8 . The subscript is meant to indicate that the first submatrix is created by excluding the row and column labelled $\$ 0$.

Note 9. With a little algebra, one can easily show that $M_{\$ 0}=6 \times M-5 \times M_{-\$ 0}$.

Note 10. We also considered individuals who are jointly enrolled in SNAP and TANF during any month in year 2000 in the State of Georgia. However, since most TANF recipients also participate in SNAP, but not vice versa, the transition matrix looks very similar to those in Tables 1 and 2 . We do not include tables of these results.

Note 11. The results of estimating equation (2) for those enrolled consecutively for less than six years are suppressed since they are identical in outcome to those presented in Table 6. 